\title{
CLEAVAGE FRACTURE MICROMECHANISMS RELATED TO WPS EFFECT IN RPV STEEL
}

\author{
S. R. Bordet ${ }^{1}$, B. Tanguy ${ }^{1}$, S. Bugat ${ }^{2}$, D. Moinereau ${ }^{2}$, A. Pineau ${ }^{1}$ \\ ${ }^{1}$ Centre des Matériaux, Ecole des Mines de Paris, UMR CNRS 7633, \\ BP 87, 91003 Evry Cedex, France \\ ${ }^{2}$ EDF R\&D, Dept. MMC, Les Renardières, 77818 Moret-sur-Loing Cedex, France \\ E-mail : S.R.Bordet.98@cantab.net, benoit.tanguy@ensmp.fr, stephane.bugat@edf.fr, \\ dominique.moinereau@edf.fr, andre.pineau@ensmp.fr
}

\begin{abstract}
The main objective of this paper is to characterise the changes caused by warm pre-stress (WPS) on the cleavage fracture micromechanisms of a 18MND5 (A533B) reactor pressure vessel (RPV) steel. In this purpose, different WPS fracture test results obtained on compact tensile (CT) and notched tensile (NT) geometries are presented and compared with isothermal test data. While confirming some well-established features of WPS, these experimental results, analysed through extensive fractographic investigations and finite element (FE) calculations, demonstrate a strong material aspect to WPS. One unveiled characteristic of the WPS effect is the deactivation of particles at high temperature through plastic straining under low stress, which enables breaking, or detaching from the matrix, the most critical particles without causing unstable cleavage propagation. In 18MND5 steel, these particles are TiN and carbide particles: according to the pre-stress level and fracture geometry, there is a progressive shift from TiN- to carbide-induced cleavage, up to the replacement of both by ductile type nucleation mechanisms.
\end{abstract}

\section{Introduction}

Since the first investigations four decades ago, a large number of experiments on ferritic steels have confirmed the existence of a warm pre-stress (WPS) effect, which describes the effective enhancement of the cleavage fracture toughness at low temperature following the application, at a higher temperature, of a stress intensity factor (SIF) which exceeds the fracture toughness of the virgin material at low temperature. These experiments allowed for the establishment of the so-called 'conservative principle', which states that no fracture will occur if the applied SIF decreases (or is held constant) while the temperature at the crack-tip decreases, even if the fracture toughness of the virgin material is exceeded. In structural integrity assessments involving a prior overload or a thermal transient, such as that of a nuclear pressure vessel subjected to a pressurized thermal shock (PTS) consecutive to a loss of coolant accident (LOCA), such a principle is of great importance in the evaluation of the safety margins.

Three main reasons have been advanced to explain the WPS effect: the blunting of the crack tip at high temperature, the formation of high compressive stresses ahead of the crack tip on elastic unloading, and a change in the cleavage fracture micromechanisms induced by plastic deformation. While all these factors certainly contribute to the effective toughness enhancement following WPS, their relative incidence on the fracture risk is not easily established. In this paper, the choice is made to focus mainly on the cleavage fracture micromechanisms following WPS, as a first step towards better quantifying the individual contributions of crack tip blunting and residual stresses. In this purpose, different WPS fracture test results obtained on compact tensile (CT) and notched tensile (NT) geometries, made of 18MND5 (A533B) reactor pressure vessel (RPV) steel, are presented and compared with isothermal test data. The WPS-induced changes in the cleavage initiation mechanisms are analysed in the light of extensive fractographic investigations and finite element (FE) calculations.

\section{Material characteristics}

The material is a $200 \mathrm{~mm}$ thick rolled plate of 18MND5 RPV steel produced by Creusot Loire Industrie in 1995 to meet the requirements of the French RCC-M standard [1]. Its chemical composition is $0.19 \mathrm{C}-1.5 \mathrm{Mn}-0.23 \mathrm{Si}-0.66 \mathrm{Ni}-0.17 \mathrm{Cr}-0.485 \mathrm{Mo}-$ $0.084 \mathrm{Cu}-<0.001 \mathrm{~S}-0.004 \mathrm{P}-0.011 \mathrm{Al}-0.004 \mathrm{~V}-0.006 \mathrm{Ti}$ (wt pct). Its conventional mechanical properties at room temperature in the rolling (L) direction are: $\mathrm{E}=205300 \mathrm{MPa}, \sigma_{y s}=517 \mathrm{MPa}, \mathrm{UTS}=650 \mathrm{MPa}, \mathrm{e}_{\mathrm{f}}$ (elongation at fracture) $=25 \%$.

The scanning electron micrograph in Fig. 1 reveals a tempered bainitic microstructure. Most carbides in $18 \mathrm{MND5}$ are elongated and tend to break normal to their long axis under tensile straining: the carbide characteristic length with regard to 


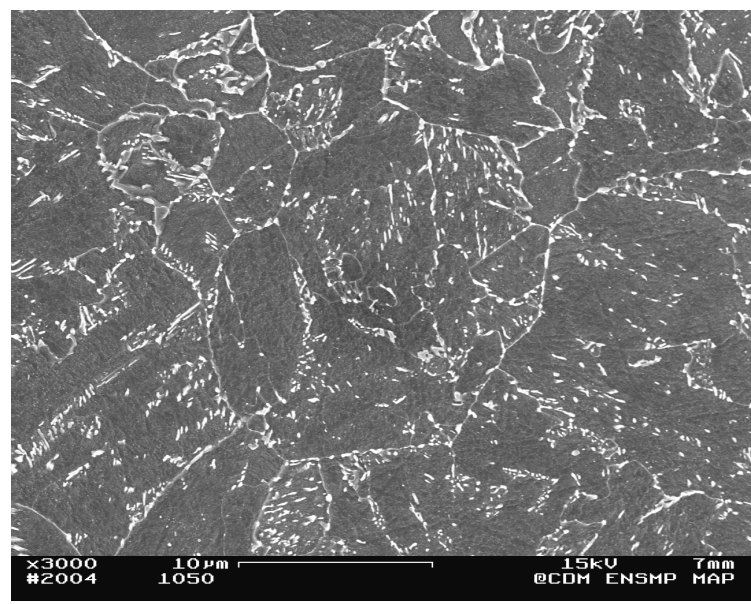

Figure 1. Scanning electron micrograph of 18MND5 RPV steel microstructure

microcrack formation is therefore the carbide width, whose maximum size was measured as being close to $0.7 \mu \mathrm{m}$ (the last figure indicates that a significant fraction of the carbides exceed the micron in length). The main types of inclusions, determined by X-ray microanalysis, are the following: Manganese sulfides (MnS), titanium nitrides (TiN), oxides of $\mathrm{Al}, \mathrm{Mg}, \mathrm{Si}$ and $\mathrm{Ca}$. All these inclusions tend to be clustered and are often bound together.

\section{Mechanical tests}

Full details of the mechanical tests are given in [2]. The fracture specimens, all tested under quasi-static conditions, consist of: notched tensile (NT) specimens with a notch radius of $2.4 \mathrm{~mm}$, a minimal section of $6 \mathrm{~mm}$, and a maximal section diameter of $10.8 \mathrm{~mm}$,

- compact tensile (CT) toughness test specimens, with a thickness of $25 \mathrm{~mm}$ and an effective crack length to width ratio, $\mathrm{a}_{0} / \mathrm{W}$, of 0.5 .

Each pre-stressed NT specimen was subjected to a different warm pre-stress cycle at room temperature. Three specimens were loaded in tension only to 20,30 and $40 \%$ mean strain (calculated as $\varepsilon_{\text {mean }}=2 \cdot \ln \left(\phi_{0} / \phi\right)$, where $\phi$ and $\phi_{0}$ are respectively the actual and initial minimum section diameters), two others in compression only to -20 and $-30 \%$, and four others strained to 5 , 10,20 and $30 \%$ in tension and then by the same amount in compression, so as the diameter $\phi$ returned to its initial value. Four notched tensile specimens of virgin material were first broken at $-150^{\circ} \mathrm{C}$, which is the temperature at which the pre-stressed CT specimens are re-loaded (see below). All NT specimens failed at a mean strain in excess of $40 \%$. As extensive plastic deformation at low temperature may partially hide or cancel the warm pre-stress effect on cleavage, it was decided to reload the pre-stressed NT specimens in liquid nitrogen rather than at $-150^{\circ} \mathrm{C}$ : the temperature, measured on the specimen surface, consistently stabilized around $-188^{\circ} \mathrm{C}$. This temperature allowed inducing cleavage after a limited amount of re-activated plastic flow in the pre-stressed specimen; furthermore, the mean fracture strain was dramatically decreased in the ten NT specimens of virgin material that were also tested in liquid nitrogen for comparison (from $40 \%$ in the isothermal tests at $-150^{\circ} \mathrm{C}$ to less than $4 \%$ at $-188^{\circ} \mathrm{C}$ ). All fracture test results are summarised in Table 1. It is seen that the overall trend is an increase of the mean true stress at fracture with the amount of pre-strain. More specifically, the specimens strained in tension only display the largest fracture stress, the specimens strained in compression fail at the lowest stress, and the specimens pre-deformed in tension-compression lie between the two. FE evaluations of the local fracture stresses, presented below, show a similar trend.

Fig. 2 presents the whole set of WPS experiments on the CT specimens together with isothermal toughness results already available on the lower shelf [3]. Note that all values of K presented here, at WPS, loading and fracture levels, are elastic values, thereafter noted $\mathrm{K}_{\mathrm{el}}$, calculated according to:

$$
\mathrm{K}_{\mathrm{el}}=\frac{P}{B W^{1 / 2}} f\left(a_{0} / W\right)
$$

where $P$ is the applied load, $B$ is the thickness, $W$ is the specimen width, $a_{0}$ is the crack size and $f$ is a geometrical factor given by ASTM E1820-01 [4]. Three different WPS cycles were conducted: LUCF (Load-Unload-Cool-Fracture), LCF (Load-CoolFracture) and LCIKF (Load-Cool-Increasing K-Fracture). All corresponding toughness results, as well as two additional toughness values of isothermal tests at $-150^{\circ} \mathrm{C}$, are reported in Table 2 . 


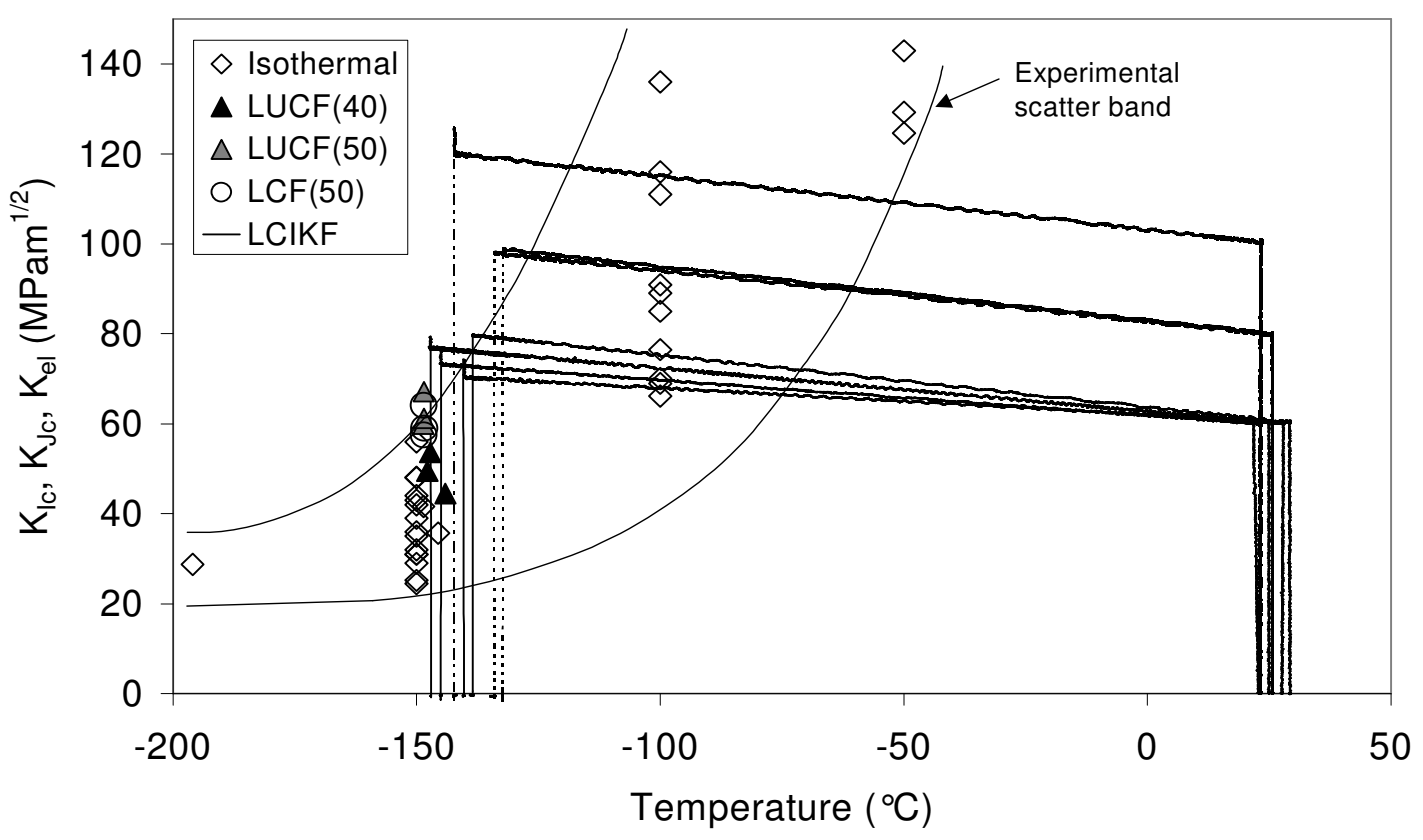

Figure 2. Experimental LUCF, LCF and LCIKF cycles on CT-25 specimen, together with isothermal toughness test results on the lower shelf and transition region. In the legend, numbers in brackets designate the value of $\mathrm{K}_{\text {wps }}$ in MPa $\sqrt{\mathrm{m}}$.

The LUCF cycles consisted in loading the specimen to $\mathrm{K}_{\mathrm{wps}}=40$ and $50 \mathrm{MPa} \sqrt{\mathrm{m}}$ at room temperature, unloading, cooling under load control to $-150^{\circ} \mathrm{C}$ and then reloading to fracture. Three toughness specimens were tested in each case. For $\mathrm{K}_{\text {wps }}=$ $40 \mathrm{MPa} \sqrt{\mathrm{m}}$, all obtained fracture toughness values are in excess of $\mathrm{K}_{\text {wps }}$, which conforms to the WPS principle. Although the toughness values still lie within the toughness scatter band of the virgin material at $-150^{\circ} \mathrm{C}$, as shown in Fig. 2 , which is expected for such a small $\mathrm{K}_{\text {wps }}$, all three values are higher than the $63.2 \%$ fracture probability toughness $\mathrm{K}_{0}$ of the virgin material (equal to $40.6 \mathrm{MPa} \sqrt{\mathrm{m}}$ ), which suggests that there is indeed a small but effective WPS effect. This is comforted by the three LUCF tests with $\mathrm{K}_{\text {wps }}=50 \mathrm{MPa} \sqrt{\mathrm{m}}$ : in this case, all toughness values exceed not only $\mathrm{K}_{\text {wps, }}$, but also all the available toughness values for the virgin material at $-150^{\circ} \mathrm{C}$.

The three LCF cycles, which consisted in pre-loading the specimen at room temperature to $\mathrm{K}_{\text {wps }}=50 \mathrm{MPa} \sqrt{\mathrm{m}}$, cooling it down to $-150^{\circ} \mathrm{C}$ under constant applied SIF (i.e. $\mathrm{K}_{\text {applied }}=\mathrm{K}_{\text {wps }}$ ), and then re-loading at $-150^{\circ} \mathrm{C}$, again confirm the WPS effect. All specimens survived the transient and failed during the re-loading stage. As expected, for a same $\mathrm{K}_{\text {wps }}$ of $50 \mathrm{MPa} \vee \mathrm{m}$, the shift in toughness at $-150^{\circ} \mathrm{C}$ following the LCF cycle is on average greater than for the LUCF cycle, even if the scatter of the toughness results means that one of the LUCF toughness values was higher than two of the values obtained after the LCF cycle.

The LCIKF tests were conducted as follows. The CT specimen was first loaded to a pre-stress value of 60,80 or $100 \mathrm{MPa} \sqrt{\mathrm{m}}$ at room temperature. The specimen was then cooled down in an environmental test chamber. A computer continuously recorded the specimen temperature by means of spot-welded thermocouples and controlled the test machine so as to describe the specified transient $(-\Delta \mathrm{K} / \Delta \mathrm{T})$ between room temperature and $-150^{\circ} \mathrm{C}$. If the specimen survived the transient, the specimen was reloaded as for an isothermal test. Due to noise in the electrical signals and in the response of the hydraulic system, however, the test machine reloaded for temperatures comprised between -140.4 and $-147.1^{\circ} \mathrm{C}$. Nevertheless, it is important to note that, for these specimens, $\mathrm{K}_{\text {frac }}$ in all cases exceeded the targeted (end of transient) $\mathrm{K}_{\mathrm{el}}$ at $-150^{\circ} \mathrm{C}$ (equal to $\left.\mathrm{K}_{\mathrm{wps}}+\Delta \mathrm{K}\right)$, so that it can be considered that the latter value would nevertheless have been reached, if these perturbations had not been present.

Several interesting observations can be made from the LCIKF test results listed in Table 2:

- All specimens, whether they broke during the transient or during reloading at $-150^{\circ} \mathrm{C}$, passed through the experimental toughness scatter band of the virgin material.

- The specimens with a $\mathrm{K}_{\text {wps }}=60 \mathrm{MPa} \sqrt{\mathrm{m}}$ and a SIF increment $\Delta \mathrm{K}$ of 10,13 and $17 \mathrm{MPa} \sqrt{\mathrm{m}}$ survived the transient, whereas the specimen with a $\Delta \mathrm{K}$ of $20 \mathrm{MPa} \sqrt{\mathrm{m}}$ failed. None of these specimens had a final $\mathrm{K}_{\text {frac }}$ exceeding $\mathrm{K}_{\text {wps }}$ by more than $20 \mathrm{MPa} \sqrt{\mathrm{m}}$.

- Both specimens with a $\mathrm{K}_{\text {wps }}=80 \mathrm{MPa} \sqrt{\mathrm{m}}$ and a $\Delta \mathrm{K}$ of $20 \mathrm{MPa} \sqrt{\mathrm{m}}$ failed before meeting the target temperature. Increasing $\mathrm{K}_{\mathrm{wps}}$ to $100 \mathrm{MPa} \sqrt{\mathrm{m}}$ allows going beyond the $\Delta \mathrm{K}=20 \mathrm{MPa} \sqrt{\mathrm{m}}$ target. 
All these results suggest that the higher $\mathrm{K}_{\text {wps }}$, the higher the enhancement in toughness at low temperature (note however that an excessive pre-load may cause ductile-type damage that opposes this trend [2]). They also indicate that a minimum critical slope $(-\Delta \mathrm{K} / \Delta \mathrm{T})$ has to be exceeded to induce cleavage fracture during cooling between room temperature and $-150^{\circ} \mathrm{C}$, which further comforts the conservative principle stated in the introduction.

\begin{tabular}{|c|c|c|c|c|c|c|c|c|c|c|c|c|}
\hline \multirow[b]{2}{*}{ no. } & \multirow{2}{*}{\begin{tabular}{c|} 
Strain \\
cycle \\
at RT \\
$(\%)$
\end{tabular}} & \multirow[b]{2}{*}{$\begin{array}{l}T_{\text {frac }} \\
\left({ }^{\circ} \mathrm{C}\right)\end{array}$} & \multirow{2}{*}{$\begin{array}{c}\text { Mean } \\
\text { fracture } \\
\text { strain } \\
(\%)\end{array}$} & \multirow{2}{*}{\begin{tabular}{|c|} 
Mean \\
fracture \\
stress \\
$(\mathrm{MPa})$ \\
\end{tabular}} & \multicolumn{3}{|c|}{ Cleavage initiation sites } & \multirow[b]{2}{*}{$\begin{array}{l}\varepsilon_{\mathrm{p} 22} \\
(\%)\end{array}$} & \multirow[b]{2}{*}{$\begin{array}{c}\varepsilon_{\text {p.cum }} \\
(\%)\end{array}$} & \multirow[b]{2}{*}{$\begin{array}{c}\sigma_{22} \\
(\mathrm{MPa})\end{array}$} & \multirow[b]{2}{*}{$\begin{array}{l}\text { Peak stress } \\
\text { initial } \\
\text { distance } \\
\text { from notch } \\
(\mathrm{mm})\end{array}$} & \multirow[b]{2}{*}{$\begin{array}{l}\sigma_{\text {22.peak }} \\
(\mathrm{MPa})\end{array}$} \\
\hline & & & & & $\begin{array}{l}\text { Distance } \\
\text { from notch } \\
(\mathrm{mm})\end{array}$ & $\begin{array}{c}\text { Initial } \\
\text { distance from } \\
\text { notch }(\mathrm{mm})\end{array}$ & Nature of initiation site & & & & & \\
\hline $4 \mathrm{~B}$ & \multirow{4}{*}{ none } & -147.3 & 44.3 & 1631.3 & 1.96 & 2.45 & $\begin{array}{c}\text { Interacting ductile cracks grown } \\
\text { from a cracked TiN and a detached } \\
\text { MnS particle }\end{array}$ & 42.2 & \multirow{4}{*}{ same } & 2029.3 & \multirow{4}{*}{$\begin{array}{c}3.0 \\
\text { (centre of } \\
\text { specimen) }\end{array}$} & 2066.8 \\
\hline $3 \mathrm{~B}$ & & -147.0 & 45.9 & 1638.0 & 2.08 & 2.62 & $\begin{array}{l}\text { Ductile crack grown from a } \\
\text { cleavage microcrack formed at a } \\
\text { cracked TiN particle }\end{array}$ & 44.0 & & 2063.1 & & 2082.2 \\
\hline $4 \mathrm{H}$ & & -149.5 & 42.1 & 1646.0 & 1.62 & 2.01 & \multirow{2}{*}{$\begin{array}{l}\text { Ductile crack grown from a stringer } \\
\text { of detached MnS particles }\end{array}$} & 39.8 & & 1931.2 & & 2045.3 \\
\hline $15 \mathrm{M}$ & & -149.0 & 47.8 & 1703.8 & 1.51 & 1.92 & & 45.7 & & 1953.5 & & 2099.3 \\
\hline 7B & \multirow{10}{*}{ none } & \multirow{10}{*}{-188} & 2.18 & 1373.2 & 2.20 & \multirow{10}{*}{ same } & \multirow{3}{*}{ Cracked TiN particle } & 1.11 & \multirow{10}{*}{ same } & 1662.9 & \multirow{7}{*}{3.0} & 1698.1 \\
\hline $7 \mathrm{H}$ & & & 1.91 & 1356.2 & 2.28 & & & 0.82 & & \begin{tabular}{|l|}
1636.9 \\
\end{tabular} & & 1652.3 \\
\hline 8B & & & 2.21 & 1366.8 & 2.61 & & & 0.96 & & \begin{tabular}{|l|}
1693.1 \\
\end{tabular} & & 1700.9 \\
\hline $8 \mathrm{H}$ & & & 3.26 & 1373.9 & 2.60 & & Undetermined & 1.97 & & 1797.8 & & 1817.6 \\
\hline $9 \mathrm{~B}$ & & & 2.96 & 1380.6 & 2.37 & & \multirow{6}{*}{ Cracked TiN particle } & 1.70 & & 1745.9 & & 1785.9 \\
\hline $9 \mathrm{H}$ & & & 3.03 & 1370.7 & 2.08 & & & 1.99 & & 1709.2 & & 1798.4 \\
\hline 10B & & & 2.42 & 1371.1 & 2.24 & & & 1.29 & & \begin{tabular}{|l|}
1689.3 \\
\end{tabular} & & 1729.8 \\
\hline $10 \mathrm{H}$ & & & 1.37 & 1332.4 & 1.86 & & & 0.58 & & \begin{tabular}{|l|}
1537.1 \\
\end{tabular} & 2.25 & 1546.9 \\
\hline 11B & & & 1.78 & 1358.0 & 2.62 & & & 0.61 & & 1626.6 & \multirow{5}{*}{3.0} & 1628.3 \\
\hline $11 \mathrm{H}$ & & & 1.81 & 1350.5 & 1.71 & & & 1.09 & & \begin{tabular}{|l|}
1565.1 \\
\end{tabular} & & 1635.3 \\
\hline $3 H$ & \pm 5 & \multirow{9}{*}{-188} & 4.44 & 1480.7 & 1.99 & 2.04 & \multirow{2}{*}{$\begin{array}{c}\text { Cracked grain } \\
\text { boundary carbide }\end{array}$} & 3.76 & 10.07 & 1709.6 & & 1766.4 \\
\hline $1 M$ & \pm 10 & & 9.00 & 1580.9 & 1.90 & 1.99 & & 7.72 & 21.99 & 1911.6 & & 2000.2 \\
\hline $7 \mathrm{M}$ & \pm 20 & & 10.18 & 1634.6 & 1.52 & 1.61 & \multirow{2}{*}{$\begin{array}{l}\text { Hole around a stringer of detached } \\
\text { MnS particles }\end{array}$} & 9.53 & 42.08 & 1968.4 & & 2114.5 \\
\hline $4 \mathrm{M}$ & \pm 30 & & 4.69 & 1507.8 & 1.26 & 1.27 & & 5.24 & 57.07 & 1841.7 & 1.8 & 1860.2 \\
\hline 2B & -10 & & 6.10 & 1533.5 & 2.18 & 2.14 & \multirow{3}{*}{ Cracked TiN particle } & -3.21 & 10.98 & \begin{tabular}{|l|}
1747.7 \\
\end{tabular} & 3.0 & 1801.4 \\
\hline $5 \mathrm{H}$ & -20 & & 2.63 & 1377.9 & 1.65 & 1.48 & & -14.43 & 177.21 & 1574.8 & 1.36 & 1576.6 \\
\hline $14 \mathrm{M}$ & +20 & & 8.30 & 1718.3 & 1.46 & 1.69 & & 25.71 & 25.72 & 1976.6 & \multirow{3}{*}{3.0} & 2146.2 \\
\hline $6 \mathrm{M}$ & +30 & & 5.76 & \begin{tabular}{|l|l|}
1719.7 \\
\end{tabular} & 2.31 & 2.75 & Hole around a detached inclusion & 33.04 & 33.04 & 2204.5 & & 2210.6 \\
\hline $11 \mathrm{M}$ & +40 & & 2.15 & 1708.9 & 1.50 & 1.85 & $\begin{array}{l}\text { Interacting holes around detached } \\
\text { inclusions }\end{array}$ & 39.39 & 39.40 & 2127.4 & & 2237.5 \\
\hline
\end{tabular}

Table 1. Notched tensile (NT) test results. Data related to TiN induced cleavage are in bold characters, while those related to carbide induced cleavage are in italic.

\begin{tabular}{|c|c|c|c|c|c|c|c|c|c|c|c|c|c|c|c|}
\hline \multirow[t]{2}{*}{ no. } & \multirow{2}{*}{$\begin{array}{l}\text { Cycle } \\
\text { type }\end{array}$} & \multirow{2}{*}{$\begin{array}{l}T_{\text {frac }} \\
\left({ }^{\circ} \mathrm{C}\right)\end{array}$} & \multirow{2}{*}{ 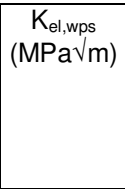 } & \multirow{2}{*}{$\begin{array}{c}\text { Targeted } \\
\mathrm{K}_{\mathrm{el}} \\
(\mathrm{MPa} \sqrt{\mathrm{m}})\end{array}$} & \multirow{2}{*}{$\begin{array}{c}\mathrm{K}_{\mathrm{el}, \mathrm{frac}} \\
(\mathrm{MPa} \vee \mathrm{m})\end{array}$} & \multirow{2}{*}{$\begin{array}{c}\text { Breaks } \\
\text { before } \\
\text { target }\end{array}$} & \multicolumn{4}{|c|}{ Cleavage initiation sites } & \multirow{2}{*}{$\begin{array}{l}\varepsilon_{\mathrm{p} 22} \\
(\%)\end{array}$} & \multirow{2}{*}{$\begin{array}{c}\varepsilon_{p, \text { cum }} \\
(\%)\end{array}$} & \multirow{2}{*}{$\begin{array}{c}\sigma_{22} \\
(\mathrm{MPa})\end{array}$} & \multirow[b]{2}{*}{\begin{tabular}{|c|} 
Peak \\
stress \\
distance \\
from \\
crack tip \\
$(\mathrm{mm})$ \\
\end{tabular}} & \multirow{2}{*}{$\begin{array}{l}\sigma_{22, \text { ear }} \\
(\mathrm{MPa})\end{array}$} \\
\hline & & & & & & & 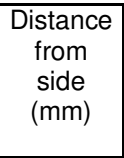 & $\begin{array}{l}\text { Distance } \\
\text { from } \\
\text { crack tip } \\
(\mathrm{mm})\end{array}$ & $\begin{array}{l}\text { Initial } \\
\text { distance } \\
\text { from } \\
\text { crack tip } \\
\text { (mm) }\end{array}$ & $\begin{array}{c}\text { Nature of } \\
\text { initiation } \\
\text { site }\end{array}$ & & & & & \\
\hline D1H & \multirow[t]{2}{*}{ Isoth. } & -145.6 & \multirow[t]{2}{*}{ none } & \multirow[t]{2}{*}{ - } & 35.7 & \multirow[t]{2}{*}{ - } & 4.7 & 0.034 & 0.036 & \multirow{3}{*}{ TiN } & 0.157 & 0.162 & 1927 & 0.009 & 2294 \\
\hline D4H & & -148.6 & & & 41.6 & & 9.6 & 0.078 & 0.08 & & 0.074 & 0.079 & 1791 & 0.013 & 2311 \\
\hline D3B & \multirow{6}{*}{ LUCF } & \begin{tabular}{|l|}
-144.1 \\
\end{tabular} & \multirow{3}{*}{40} & \multirow{6}{*}{-} & 44.5 & \multirow{6}{*}{ - } & 6.1 & 0.037 & 0.041 & & 0.193 & 0.375 & 2007 & 0.015 & 2448 \\
\hline $\mathrm{D} 6 \mathrm{H}$ & & -147.2 & & & 49.5 & & 2.5 & 0.01 & 0.014 & Carbide & 5.0 & 6.4 & 2332 & 0.035 & 2376 \\
\hline D5H & & -147.8 & & & 53.6 & & 4.2 & 0.043 & 0.048 & TiN & 0.258 & 0.394 & 2122 & 0.020 & 2441 \\
\hline G2H & & -148.5 & \multirow{3}{*}{50} & & 57.5 & & 11.1 & 0.036 & - & Sub-surf. & & \multirow{4}{*}{ - } & \multirow{4}{*}{ - } & - & - \\
\hline G4H & & -148.4 & & & 59 & & 3.6 & 0 & 0 & Micro-duct. & & & & 0.020 & 2360 \\
\hline G1B & & -148.5 & & & 64.1 & & 6.3 & 0.128 & - & Sub-surf. & & & & - & - \\
\hline G2B & \multirow{3}{*}{ LCF } & -148.6 & \multirow{3}{*}{50} & \multirow{3}{*}{ - } & 59.9 & \multirow{3}{*}{-} & 4.3 & 0.065 & - & Sub-surf. & & & & - & - \\
\hline G1H & & -148.5 & & & 61.2 & & 8.5 & 0.085 & 0.091 & \multirow{3}{*}{ TiN } & 0.138 & 0.145 & 1945 & 0.020 & 2357 \\
\hline G4B & & -148.5 & & & 67.1 & & 2.7 & 0.12 & 0.127 & & 0.141 & 0.148 & 1947 & 0.025 & \begin{tabular}{|l|l|}
2377 \\
\end{tabular} \\
\hline D3H & & \begin{tabular}{|l|}
-140.4 \\
\end{tabular} & & 70 & 74.4 & $\mathrm{n}$ & 6.3 & 0.217 & 0.226 & & 0.094 & 0.100 & 1768 & 0.029 & 2373 \\
\hline D5B & & -144.9 & 60 & 73 & 77.1 & $n$ & 6.7 & 0.028 & 0.037 & Carbide & 1.7 & 1.8 & 2353 & 0.014 & 2461 \\
\hline D1B & & \begin{tabular}{|l|}
-147.1 \\
\end{tabular} & & 77 & 79.4 & $\mathrm{n}$ & 3.8 & 0.052 & - & Sub-surf. & - & - & - & - & 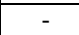 \\
\hline D2H & LCIKF & \begin{tabular}{|l|}
-138.5 \\
\end{tabular} & & 80 & 79.9 & $y$ & 8.3 & 0.151 & 0.161 & TiN & 0.146 & 0.153 & 1892 & 0.034 & 2375 \\
\hline D6B & & -134 & 80 & 100 & 98.3 & $y$ & 4.9 & 0.15 & 0.167 & TiN & 0.207 & 0.214 & 1953 & 0.052 & 2291 \\
\hline D2B & & -132.3 & & 100 & 99 & $y$ & 5.2 & 0.318 & - & Sub-surf. & - & - & - & - & - \\
\hline D4B & & \begin{tabular}{|l|}
-142.3 \\
\end{tabular} & 100 & 120 & 126 & $n$ & 10.9 & 0.419 & 0.447 & TiN & 0.147 & 0.154 & 1949 & 0.086 & 2403 \\
\hline
\end{tabular}

Table 2. Compact tensile (CT) test results. Data related to TiN induced cleavage are in bold characters, while those related to carbide induced cleavage are in italic. 


\section{Fractographic study of the cleavage nucleation sites}

Fracture surfaces of all NT and CT specimens have been examined on a scanning electron microscope (SEM): the site of cleavage initiation has been searched following tear ridges and river lines, the nature of the particle responsible for initiation identified by X-ray micro-analysis (when its size allowed it), and its distance from the crack or notch tip measured. Note that all distances given hereafter, unless stated otherwise, refer to the deformed configuration at fracture.

All NT samples tested at $-150^{\circ} \mathrm{C}$ failed in a similar way: macroscopic cleavage was initiated in the vicinity of a zone of ductile crack growth, which developed either from detached and/or cracked MnS and TiN particles, or TiN-induced cleavage microcracks rapidly stopped at grain boundaries (Fig. 3). The extensive ductile crack growth suggests that the particles broke and/or separated from the matrix early in the loading history, when insufficient tensile stress was available to sustain longrange cleavage propagation, hence the microcrack arrests at the particle/matrix interface or at the grain boundary. Further loading was then necessary to cause final fracture, by two concomitant processes: first by globally raising the mean tensile stress that ensures long-range cleavage instability, second by locally concentrating the stress by ductile crack growth from the arrested microcracks or holes so as to induce cleavage re-initiation.

Out of the ten NT specimens of virgin material that were tested in liquid nitrogen, nine failed at a TiN inclusion, whether bound to another particle (e.g. MnS) or not. The origin of cleavage in one of the specimens could not be categorically determined, but likely lay below the fracture surface. The fact that $90 \%$ of the specimens failed at a TiN particle clearly demonstrates that TiN particles, when not prematurely broken (see discussion below), constitute preferential sites for cleavage nucleation in the virgin material. This contrasts with the results obtained on the pre-strained NT specimens, also tested in liquid nitrogen. Out of nine specimens, cleavage initiated from TiN cracking in only three specimens: the two specimens pre-strained in compression only,

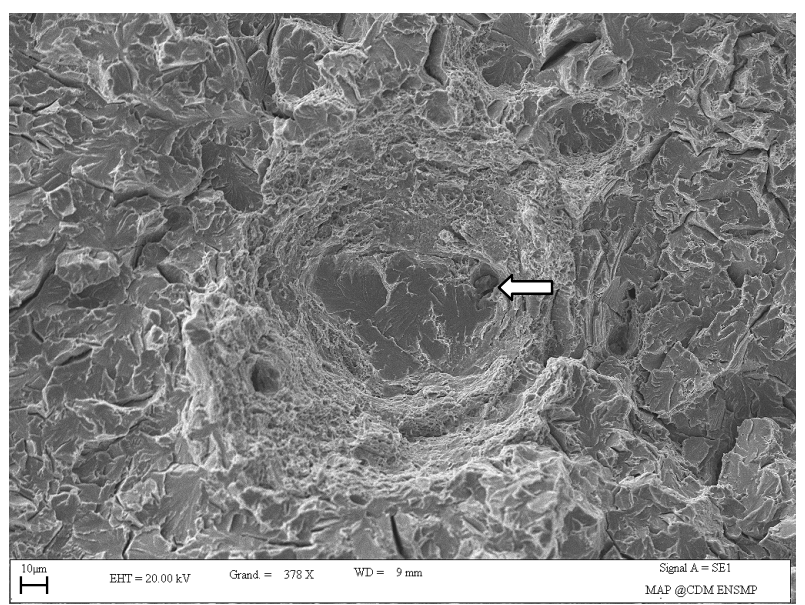

Figure 3: Cleavage initiation site in NT specimen (3B) tested at $-150^{\circ} \mathrm{C}$. Macroscopic cleavage started at a ductile crack grown from a cleavage microcrack stopped at a grain boundary. The arrested microcrack was nucleated by the cracking of a TiN particle (indicated by the arrow) bound to a MnS particle.

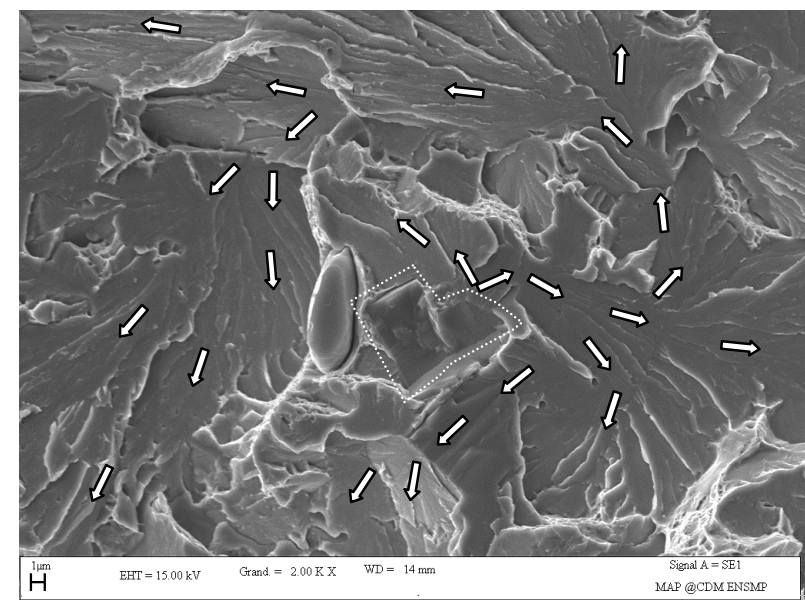

Figure 4. Cleavage initiation site of warm pre-stressed CT specimen (D2H). Cleavage initiated at a cracked TiN particle (circumscribed by the white dotted line) lying next to a MnS particle loosely bound to the matrix. The arrows indicate the paths of cleavage propagation. Note the zones of ductile tearing between these cleavage paths. 
and the specimen subjected to a tensile pre-strain of $20 \%$. Two initiated at a grain boundary carbide: these are the specimens subjected to the two lowest tension-compression cycles, namely $\pm 5 \%$ and $\pm 10 \%$. The four other specimens - subjected to the largest pre-strains - failed in the vicinity of holes formed around MnS stringers or inclusions.

These results therefore suggest a change in the most critical initiation mechanism at low temperature, depending on the level and direction of pre-straining. While compressive pre-strain does not seem to much affect the potentiality of TiN particles for initiating cleavage, tensile pre-strain appears to have an attenuating effect. Considering that tensile pre-strain causes early cracking of the most noxious TiN particles, the apparition of carbides as cleavage nucleators for relatively small pre-strains suggests that their contribution to cleavage is simply precluded by initiation at TiN particles in the virgin material. Carbides can also be held responsible for cleavage initiation in the vicinity of the holes, around which microductile damage takes place, especially at grain boundaries: the latter induces stress concentration and higher local strain rates, which will promote both carbide cracking and cleavage initiation.

In the CT geometry, cleavage predominantly initiated at TiN particles, alone or bound to other particles (Fig. 4), except in two specimens, where the initiating particle is a grain boundary carbide, and a third one where cleavage started at a zone of microductile damage (holes) right at the crack tip. For the latter mechanism, it is possible that the cracking of a carbide was ultimately responsible for cleavage initiation, but this could not be ascertained. In five specimens, the initiation site was located below the surface: in this case, the distances reported in Table 2 correspond to the region of re-initiation on the visible fracture surface. These distances can therefore significantly differ from the distance to the actual initiation site. To sum up, in terms of frequency, $55 \%$ of the CT specimens initiated cleavage at TiN particles, $11 \%$ at carbides, $6 \%$ at a zone of micro-ductility, and $28 \%$ at undetermined sites.

\section{Analysis of the local mechanical conditions for cleavage initiation}

Based on the location of the initiation site in the deformed NT and CT geometries, the local normal (opening) stress and plastic strain at fracture were evaluated from finite element calculations, whose details can be found in [2]. For simplification, it was assumed that, for both NT and CT geometries, the initiation points lay on the mid-plane normal to the loading direction [2]. An axisymmetric FE model was used for the NT geometry, while 2D plane strain modelling was used for the CT geometry.

Tables 1 and 2 list the local normal stress and strain values at fracture for all different tests, except the CT tests where cleavage initiated below the surface and the one right at the crack tip. The peak stress value at fracture is also reported, as well as its current or initial position. Plotting the local fracture stresses as a function of the local fracture strains in Fig. 5 enables to mechanically characterise and distinguish the different cleavage initiation modes. It is seen that:

- Cleavage nucleation by TiN and carbide cracking is characterised by significantly higher local tensile stress and lower cumulated plastic strain in the CT geometry than in the NT geometry. To explain this difference, one can argue that, for reaching the critical stress within the particles, larger plastic strains have to develop in the NT geometry to compensate for the lower tensile stresses through plastic loading of the particles. Another explanation is that the larger fracture process zone in the NT geometry makes it more likely to sample the most critical TiN particles present in 18MND5, hence a lower critical stress for both cleavage nucleation and propagation.

- Carbide cracking tends to occur under larger plastic strain and stress levels than TiN cracking.

- For both NT and CT geometries, there is a general tendency for the local stress to increase with plastic strain. It is however interesting to note that, for the NT test results, compressive pre-strain (whether followed by tensile pre-strain or not) tends to lower the critical local stress for cleavage.

- There is a clear separation between particle-induced and ductile type cleavage nucleation. The latter includes cleavage nucleation at holes (pre-stressed NT tests at $-188^{\circ} \mathrm{C}$ ) and ductile crack (isothermal NT tests at $-150^{\circ} \mathrm{C}$ ). All cumulated local plastic strains accompanying ductile type cleavage initiation are above $30 \%$. The local stress values are on average higher for ductile type cleavage initiation: this is another indication that plastic pre-strain at room temperature (i.e. under insufficient tensile stress to allow microcrack propagation) progressively deactivated, through cracking or decohesion, the $\mathrm{TiN}$ and carbide particles that would otherwise have initiated cleavage at low temperature.

The WPS effect on the cleavage initiation mechanisms is more difficult to characterise in the CT geometry. Fig. 6 is a plot of the distance of the cleavage initiation sites from the crack tip as a function of the crack tip opening displacement, $\delta_{\mathrm{el}}$, at fracture, calculated as:

$$
\delta_{\mathrm{el}}=\mathrm{K}_{\mathrm{el}}^{2} / 2 \sigma_{y s} E\left(1-v^{2}\right)
$$

Also represented in Fig. 6 is the linear fit of the distances of the peak stress location relative to the crack tip at fracture. Several remarks and deductions can be made:

- The distance $d_{\text {peak stress }}$ between the peak stress location and the crack tip varies linearly with the CTOD, namely: $d_{\text {peak }}$ stress $\approx 1.78 \times \delta_{\mathrm{el}}$, for the deformed configuration. This relationship is valid for all cycles and WPS levels.

- All identified TiN particles that initiated catastrophic cleavage are located beyond the peak stress location with regard to the crack tip. In other words, they are located in a region that has not experienced the peak stress, characterised by a stress slightly lower than the peak stress and by low plastic strains (see Table 2). Despite the expected scatter, there is, 
as for the peak stress, an overall proportional relationship between the TiN initiation site location and the CTOD at fracture: $d_{\text {initiation site }} \approx 8.33 \times \delta_{\text {el. }}$. This linear relationship expresses the necessity to remain close from the peak stress region, and thus testifies to the determinant role of high tensile stresses in propagating cleavage.

- The fact that $d_{\text {initiation site }}$ is on average 4 times greater than $d_{\text {peak stress }}$ indicates that the TiN population is scarce in the material. Another possible reason is a spatial shift caused by the deactivation of TiN particles, close to the crack tip, during the WPS. More local measurements in isothermal tested specimens, however, are needed to quantify this shift.

- The two sites that initiated cleavage by carbide cracking are located in the immediate vicinity of the peak stress. This contrasts with the sites that initiated cleavage by TiN cracking, which are found much further away. For both particles, the peak stress location constitutes the most critical site for cleavage propagation, as the latter is stress controlled [5]. The main difference is that the carbide population is very large compared with the TiN population, which makes it much more likely to have a critical carbide at the peak stress location. Furthermore, due to their much smaller sizes (typically 5 to 10 times smaller), carbides require on average higher stresses than TiN particles to nucleate cleavage, as reflected by Tables 1 and 2. Lastly, the nearer the distance from the crack tip, the stronger the material was pre-strained, and thus the more likely that the TiN particles have been deactivated while some potentially critical carbides survived.

In small scale yielding (SSY), the region within a contour of constant stress becomes increasingly wider as the stress diminishes: the small number of TiN particles is therefore compensated by a larger critical volume for cleavage initiated by TiN particles, compared with that associated with carbides. The frequencies previously given indicates that the combination of particle size and volume concentration, with regard to the crack tip mechanical environment at $-150^{\circ} \mathrm{C}$ following the different WPS cycles, is more critical for the TiN particles than for the carbides (55\% vs. $11 \%)$. This is consistent with the observation that no cleavage initiation by carbide cracking was observed in the isothermal NT tests in liquid nitrogen. Not only is the stress intensification much lower, but the plastic zone is also much wider in the NT geometry than in the CT geometry: both accentuate the bias towards cleavage initiation by TiN cracking. Warm pre-strain at room temperature permits reducing this bias and rendering more likely the occurrence of cleavage nucleation by carbide cracking.

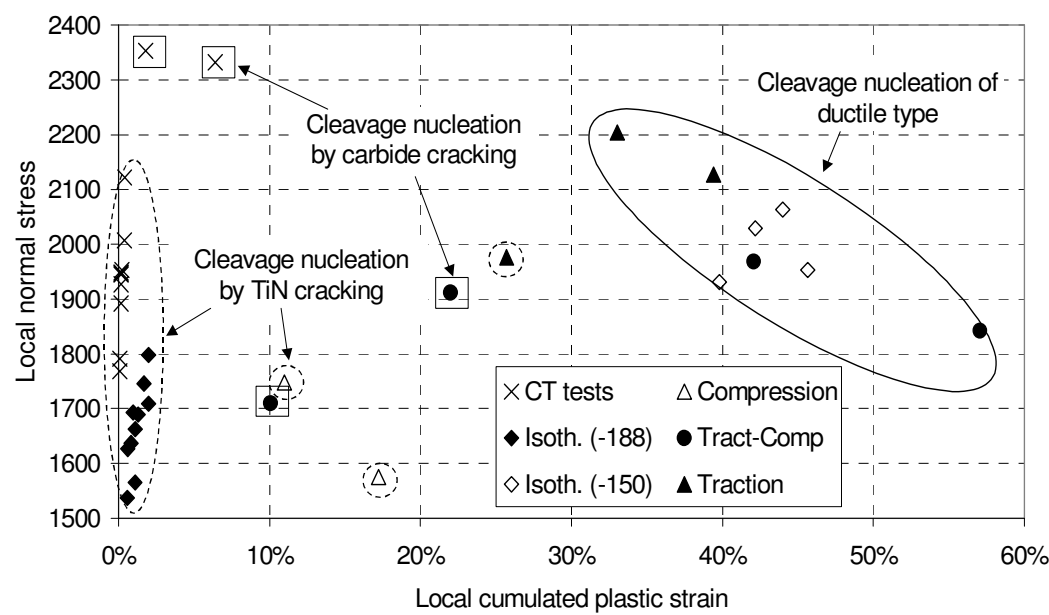

Figure 5. Local normal stresses vs. local cumulated plastic strains at fracture in the NT and CT test specimens, estimated by FE calculations for all identified cleavage initiation sites (except CT test $(\mathrm{G} 4 \mathrm{H})$ ).

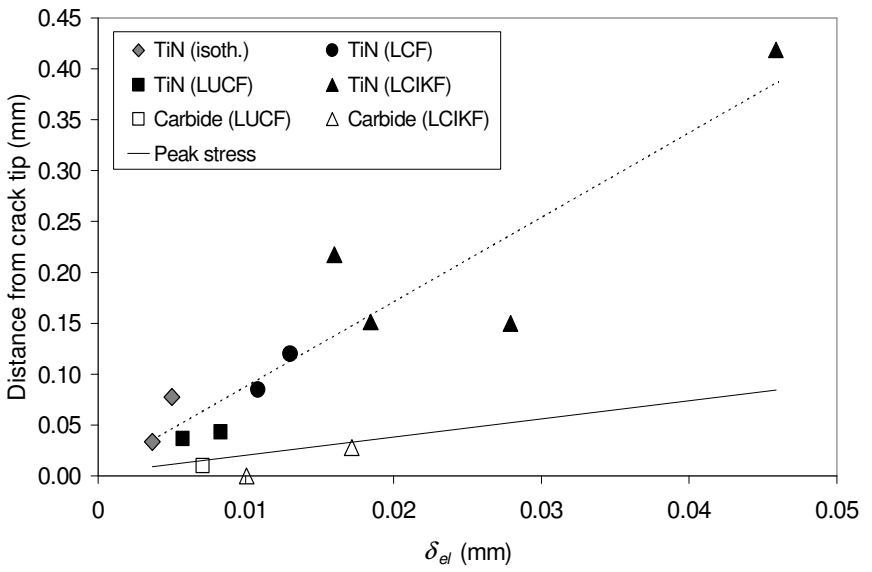

Figure 6. Distance of the cleavage initiation sites from the crack tip and best linear fit of the distances of the peak stress location from the crack tip as a function of the elastic CTOD, $\delta_{\text {el }}$. 
In the previous section, it was argued that carbide nucleated cleavage becomes more likely in the NT geometry tested in liquid nitrogen after moderate warm pre-straining $\left(\varepsilon_{p, \text { cum }}<30 \%\right)$, due to the earlier and faster deactivation of the TiN particles. The experimental observation that the TiN particles are still the main initiators for global cleavage in the CT geometry, despite relatively large pre-loads, is explained by the fact that the large strain region remains very localized at the crack tip. At a blunted, yet highly constrained, crack tip, the peak stress occurs at some distance from the crack tip (about twice the CTOD: see Fig. 6) under relatively small strains (cf. Table 2), and keeps approximately constant while moving away from the crack tip under increasing load. Reloading at low temperature not only globally raises the stress level, which allows widening the region capable of cleavage propagation, but also, for a sufficiently large applied SIF, causes the peak stress to sample material little or not affected by the WPS at high temperature, hence the continued participation of the TiN particles in cleavage initiation. In the NT geometry, the whole notched region is subjected to the warm pre-strain, so that the highest pre-strains completely deactivated the potential nucleators and led to ductile type cleavage nucleation. By contrast, in the CT specimen, the occurrence of cleavage nucleation by carbide cracking results from the complex interplay between the actual peak stress region and the WPS affected region ahead of the crack tip, and the competition with TiN cracking and other cleavage nucleation mechanisms.

\section{Conclusion}

This paper presented various WPS fracture experiments obtained on compact tensile (CT) and notched tensile (NT) geometries, made of 18MND5 (A533B) reactor pressure vessel (RPV) steel. These experiments confirmed important features of WPS, notably an increase in cleavage resistance following WPS, as well as the conservative principle. The main object of this paper was to characterise the effect of WPS on the cleavage fracture micromechanisms. Whereas this effect was clearly identifiable in the NT geometry, its manifestation was less obvious in the CT geometry due to the particular crack tip mechanical environment in SSY. One unveiled characteristic of the WPS effect is the deactivation of particles at high temperature that would have been critical at low temperature if left intact. It occurs through plastic straining under low stress, which enables breaking, or detaching from the matrix, the most critical particles without causing unstable cleavage propagation. In 18MND5 steel, these particles are TiN and carbide particles, the first being the largest and most critical, and thus the most susceptible to WPS. This deactivation modifies the competition between alternative potential cleavage nucleation mechanisms: in 18MND5, according to the pre-stress level and fracture geometry, it leads to a progressive shift from TiN to carbide-induced cleavage, up to the replacement of both by ductile type nucleation mechanisms.

Beyond the specific study of WPS, the cleavage nucleation micromechanisms identified here are useful for understanding some of the difficulties with cleavage toughness modelling, notably in the ductile-to-brittle (DBT) transition, of steels of similar composition. Recent attempts to model the transition using local approach (Beremin type [5]) cleavage models had to allow for an apparent temperature dependence of the parameter $\sigma_{u}$, to precisely take into account a possible change of micromechanisms [3]. For 18MND5 steel, this apparent temperature dependence can be attributed to a modification of the cleavage initiation micromechanisms, from cleavage initiated by TiN particle breaking at low temperature to cleavage started at grain boundary carbides in the transition, possibly helped by ductile damage (holes around broken or detached inclusions).

\section{References}

[1] RCC-M (2000). Design and construction rules for mechanical components of PWR Reactor Nuclear Island. AFCEN, FR.

[2] Bordet, S. R., Tanguy, B., Besson, J., Bugat, S., Moinereau, D., Pineau, A. Cleavage fracture of a RPV steel following warm pre-stressing: micromechanical analysis and interpretation through a new model. Submitted to Fatigue Fract Eng Mat Struct.

[3] Lefevre, W., Barbier, G., Masson, R., and Rousselier, G. (2002). A modified Beremin model to simulate the warm prestress effect. Nucl. Eng. Design, 216, 27-42.

[4] ASTM E1820-01 (2001). Standard test method for measurement of fracture toughness. ASTM standards.

[5] Beremin, F. M. (1983). A local criterion for cleavage fracture of a nuclear pressure vessel steel. Metall. Trans. A, 14A, 2277-2287. 